\title{
URBAN HEAT ISLAND IN KATHMANDU, NEPAL: EVALUATING RELATIONSHIP BETWEEN NDVI AND LST FROM 2000 TO 2018
}

\author{
Bijesh Mishra $^{1 *}$, Jeremy Sandifer ${ }^{2}$, Buddhi Raj Gyawali² \\ ${ }^{1}$ Oklahoma State University, Stillwater OK, 74075, USA \\ ${ }^{2}$ Kentucky State University, Frankfort, KY, 40601, USA \\ *Corresponding author: bijesh.mishra@okstate.edu
}

\begin{abstract}
The term "urban heat island" (UHI) describes increased surface and atmospheric temperatures in an urban core relative to surrounding non-urbanized areas. Although the phenomenon has been studied to a great extent throughout the world, it is less understood for Kathmandu, Nepal. This study used the Moderate Resolution Imaging Spectro-radiometer (MODIS) 8-day product (MOD11A2) to evaluate land surface temperatures (LSTs), the MODIS-derived Normalized Difference Vegetation Index (NDVI) 16-day product (MOD13Q1) to quantify land surface characteristics, and the Landsat-based annual land cover classification product to identify major land cover classes. We evaluated the spatial correlation between significant changes in LSTs and NDVI between 2000-2018. Overall, urban (permanently developed areas) LSTs were consistently greater than non-urban (forests and dynamic agriculture lands) LSTs; however, the rate of increase in temperature was higher outside the central Kathmandu developed urban area. Furthermore, significant changes in NDVI values over time were more widespread and not always spatially coincident with significant changes in LST values, particularly for forested land areas. These results provide insight into systematic planning of open and green areas, construction of new infrastructure in peripheral areas, and highlight the challenges in applying traditional UHI conceptual models to rapidly developing urban areas such as Kathmandu, Nepal.

Keywords: Urban Heat Island, Urbanization, Land Cover Change, Nepal, Kathmandu.
\end{abstract}

DOI: http://dx.doi.org/10.3126/jije.v8i1.22546

Copyright $\odot 2019 \mathrm{JJE}$

This work is licensed under a CC BY-NC which permits use, distribution and reproduction in any medium provided the original work is properly cited and is not for commercial purposes 


\section{Introduction}

Urbanization in Nepal has been observed since 1970 (Rimal et al. 2017; Thapa et al., 2008). In last few decades, Nepal has been among those countries with the highest urbanization rates with an annual increase of 3.0\%. This trend is expected to continue until 2050 (Bakrania, 2015; UN DESA, 2015). The areas with the greatest urbanization rates were in the Kathmandu Valley (MoUD, 2015; Thapa et al., 2008), which comprises $24.02 \%$ of the total urban area. Kathmandu's metropolitan municipality contains approximately $9.72 \%$ of the valley's total urban population (Bakrania, 2015; MoUD, 2015). Kathmandu is a major urban center with a population exceeding three million people (Chitrakar et al., 2016).

The climatic and weather conditions of the Kathmandu Valley have changed tremendously over last few decades because of rapid urbanization and conversion of a valley dominated by agricultural practices into an impervious surface layer. It has become uncomfortable and unhealthy for living as well as susceptible to disease outbreaks (Maharjan and Regmi, 2014). Throughout the year, the temperature and relative humidity are both higher in Kathmandu city (which consists of only the Kathmandu Metropolitan City area) and nearby areas compared to the surrounding valley (which includes Kathmandu, Bhaktapur, and Lalitpur districts) and nearby locations (Maharjan and Regmi, 2014; MoUD, 2015).

Kathmandu Valley's land use and land cover has changed significantly in the last four decades. Rimal et al. (2017) report that Kathmandu Valley had an average annual urban growth rate of 7.34\% between 1976 and 1989, 7.70\% between 1989 and 2002, and 5.90\% between 2002 and 2015. The city has expanded as much as $412 \%$, with the majority of land converted from agricultural land, which has changed the valley's landscape considerably (Ishtiaque et al. 2017).

The urbanization process reduces greenery and increases the number of impervious surfaces. This process causes changes in land use, land cover, and land surface characteristics that subsequently modify the local climate, moisture exchange, and ecosystem services, favoring heat trapping and storage (Cui et al., 2016; Jin et al., 2005; Lavaysse et al., 2018; Li et al., 2009). Heat trapping leads to temperature differences between urban and surrounding rural areas, with temperatures in urban areas higher than in rural areas, a phenomenon known as an "urban heat island" (UHI; Jin et al., 2005; Li et al. 2009). Increasing the population within these urban areas exacerbates UHI effects as well as exposes more people to the potential risks of UHI, such as hyperthermia (Azevedo et al., 2016). Land surface temperature (LST) is an important factor in UHI (Zakšek and Oštir, 2012). Various studies found a correlation between the Normalized Difference Vegetation Index (NDVI) and LST (Grover and Singh, 2015; Liu et al., 2015). This correlation, however, may vary based on differences in topography, demographics, and land cover attributes. 
The UHI phenomenon is important to study because it affects many aspects of life, such as infrastructure, health, energy consumption, environmental stress, and discomfort, and leads to additional costs in building infrastructure (Azevedo et al., 2016). Depending on the nature and developmental phase, UHI can have detrimental socio-economic effects (Cui et. al., 2016). Although some studies about changes in temperature have been conducted in the Kathmandu Valley, none of these studies has examined UHIs closely or the relationship of UHIs to other possible factors. Our study focuses on two major research questions: 1) Was there a significant change in LSTs of the Kathmandu Valley from 2000-2018? and 2) Was the LST change associated with a change in NDVI?

\section{Material and Method}

\subsection{Study site}

As shown in Fig. 1, Kathmandu Valley is located at a latitude of $27^{\circ} 38^{\prime} 32^{\prime \prime}-27^{\circ} 45^{\prime} 7^{\prime \prime} \mathrm{N}$ and longitude of $85^{\circ} 16^{\prime} 5^{\prime \prime}-85^{\circ} 22^{\prime} 32^{\prime \prime} \mathrm{E}$ (Thapa et al., 2008). The bowl-shaped valley has an elevation of 1,100-2,700 m (average: 1,350 m) above mean sea level (Chitrakar et al., 2016; Thapa et al., 2008; Thapa and Murayama, 2009). The valley is subdivided into five neighboring urban areas (Kathmandu, Bhaktapur, Lalitpur, Kirtipur, and Madhyapur Thimi) and 97 surrounding peri-urban and rural villages based on administrative units (Ishtiaque et al., 2017; Thapa and Murayama, 2012). The Kathmandu Metropolitan City area is flat with less than $1^{\circ}$ slope and the soil is predominantly loamy and boulder in texture (Haack and Khatiwada, 2007; Thapa et al., 2008).

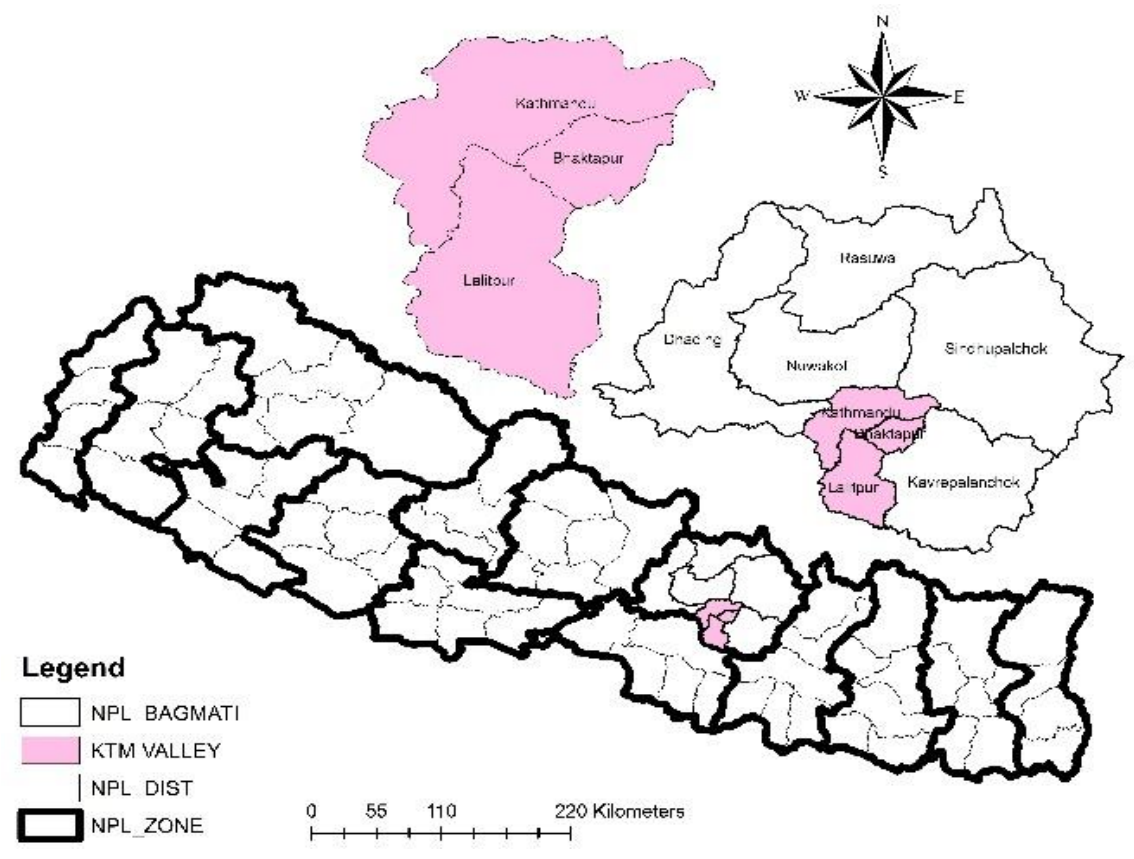

Figure 1: The Kathmandu Valley, Nepal. 


\subsection{Data Collection}

Land cover information that possesses spatially and temporally consistent attributes or that carry the same classification definitions is not widely available for Nepal (Aksha et. al. 2018). Little consensus exists on how to define the particular classes of interests best. In lieu of sampling existing land cover data, simple classification data were developed in ArcGISPro using Landsat 5 Thematic Mapper (TM) and Landsat 8 Over Land Imager (OLI) 30-meter imagery for deriving the NDVI for grouping segmented land areas into 3 broad classes: development, forest, and agriculture. For this region, cloud-free imagery data are more readily available during the months of March and October each year. Imagery data from 2000 and 2018 were used to classify all land pixels into one of three classes according to the persistence of the Landsat-derived NDVI indices over the year according to the following equation:

$\mathrm{NDVI}_{\text {October }}-\mathrm{NDVI}_{\text {March }}=\mathrm{NDVI}_{\text {minus }}$

$\mathrm{NDVI}_{\text {minus }}$ is an indication of how variable the productivity of a particular pixel is over the year. For example, an urban development or a forest has a relatively stable signal while an agricultural site as an erratic signal. This information is combined with the actual estimates of NDVI to enable us to discern the three relevant land cover classes without having to tackle the issue of defining consistent land cover classes. Developed areas were land segments with highly persistent (continuous pixels with spectral homogeneity), but relatively low magnitude NDVI values. Forest areas were land segments highly persistent with relatively high NDVI values. Agricultural areas included any and all land segments where both the persistence and relative magnitude of the NDVI values varied widely, including cropland and open fields. No less than three specific agricultural land cover classes were detected, but for the scope of this study, all were aggregated into a single class. Finally, derived land cover products were spatially resampled to 500 meters using the majority method.

This study made extensive use of the Moderate Resolution Imaging Spectro-radiometer (MODIS) instruments because of the wide systemic geographic coverage, relatively high temporal resolution, and long record length. Utilized products include the 8-day LST 1-km product (MOD11A2) and the 16-day NDVI $250 \mathrm{~m}$ product (MOD13Q1). The 500-m MODIS imagery pixel centroids were used as the individual units of observation as well as for sampling LST and NDVI data. The sampling extent was generated by converting the MODIS land cover product raster data into point-based centroids, where each centroid point retains the respective land cover types. Each centroid was sampled against all LST and NDVI layers and spatially resampled to match the 500-meter resolution of the land cover product using the cubic convolution algorithm. The extent was aimed at capturing LST and NDVI variation over time in Kathmandu and adjacent areas within the valley. The points also covered a wide range of geographic conditions and elevation heights. 


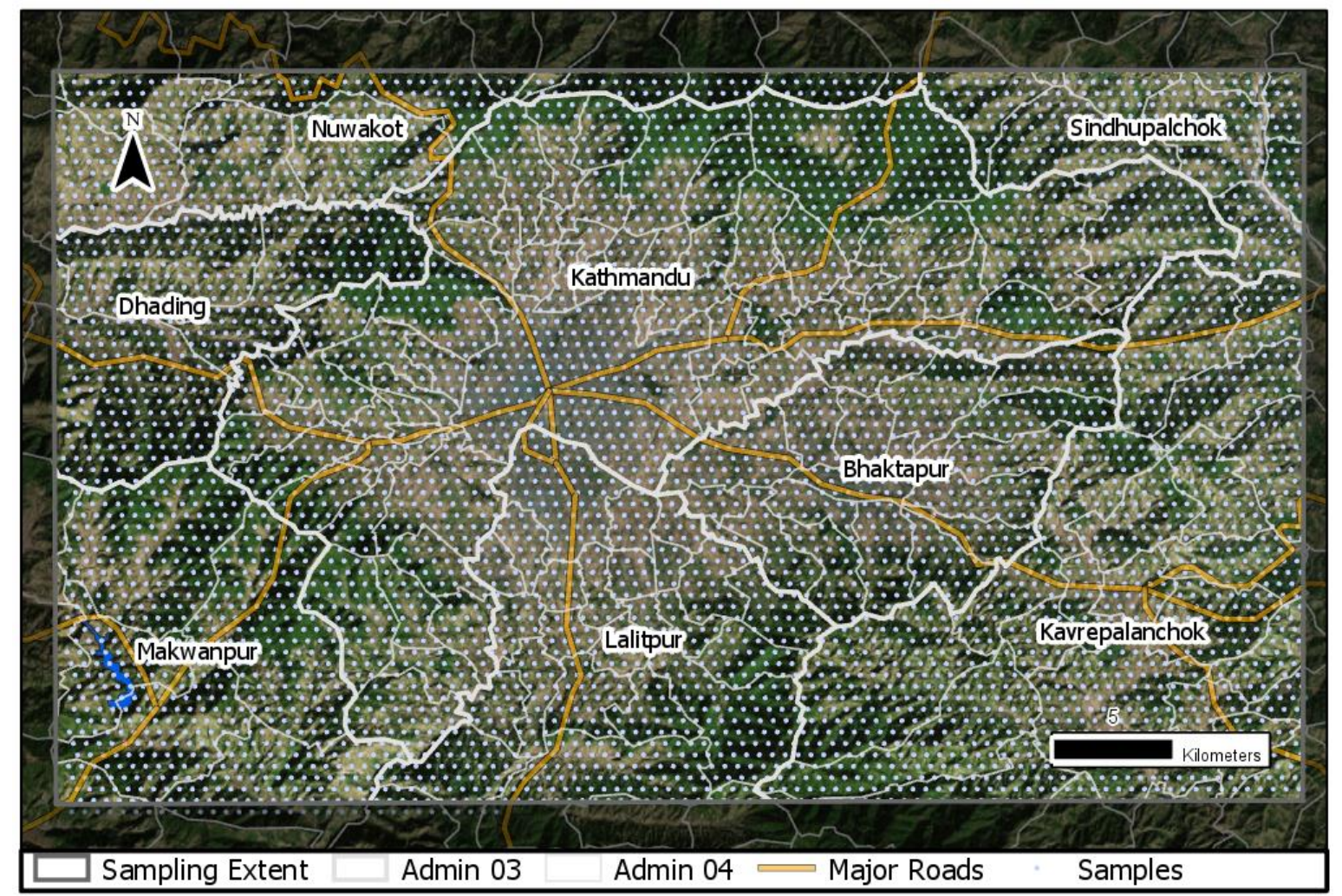

Figure 2: Sampling extent in the study area. MODIS-500-meter centroid observation units $(\mathrm{N}=6029)$

Sampling was conducted at the pixel level to quantify the distribution of change in LST and NDVI values in a spatially explicit manner not typically captured when aggregating values according to classifications or administrative zones. Pixel-based sampling and calculations on each 8-day LST image layer (N=892) and coincident 16-day NDVI image layer $(\mathrm{N}=451)$ were implemented using $\mathrm{R}$ and resulted in time series database tables covering the period 2000 to 2018 for each sample location ( $N=6269$ ). Two simple statistical methods were employed for covering the objectives regarding a) potential change over time and b) the degree to which changes in LST and NDVI are related. For evaluating change over time (magnitude and significance), the simple least-squares-regression model was specified as:

$Y=C+M \beta m+\varepsilon$

where $M$ is the length of time of each location's $(m)$ LST or NDVI value $(Y)$; $\beta$ is the slope, which equals the increase in $Y$ per time step in $M$; $C$ is the y-intercept constant; and $\varepsilon$ is the error. The generated $\beta$ coefficients described the approximate mean increase in LST and NDVI over time and any potentially significant change was based on $p$-values $(p<0.05$ ). This analysis was applied to all of the pixels separately for all dates from 2000 to 2018. Each pixel time series was grouped according to the 2018 land cover sampled for that location and by the type of land cover change experienced between 2000 and 2018 to understand how NDVIs and LSTs may be interacting differently across the types. Lastly, the degree of associations between changes in 
NDVI and LST was evaluated using the Pearson Correlation (PC) value. All data summaries, figures, and hypotheses were developed using $\mathrm{R}$ and a suite of extended packages (R Core Team, 2013).

\section{Results and Discussion}

\subsection{Change in Land Cover Distributions 2000 to 2018}

Land cover classification maps developed for the year 2000 and 2018 show a dynamic and changing landscape, including a large overall increase in developed areas of $25 \%$, particularly in the areas adjacent to pre-existing development and largely replacing land previously used for agriculture. Figure 3 highlights the spatial distributions of land cover, including a forestland cover loss of $15 \%$ and a small increase (3\%) in agricultural land compared to 2000 levels. Table 1 summarizes changes over time by the administrative regions; Kathmandu, Bhaktapur, and Lalitpur had the most substantial increases in overall development at $42 \%, 123 \%$, and $56 \%$, respectively.
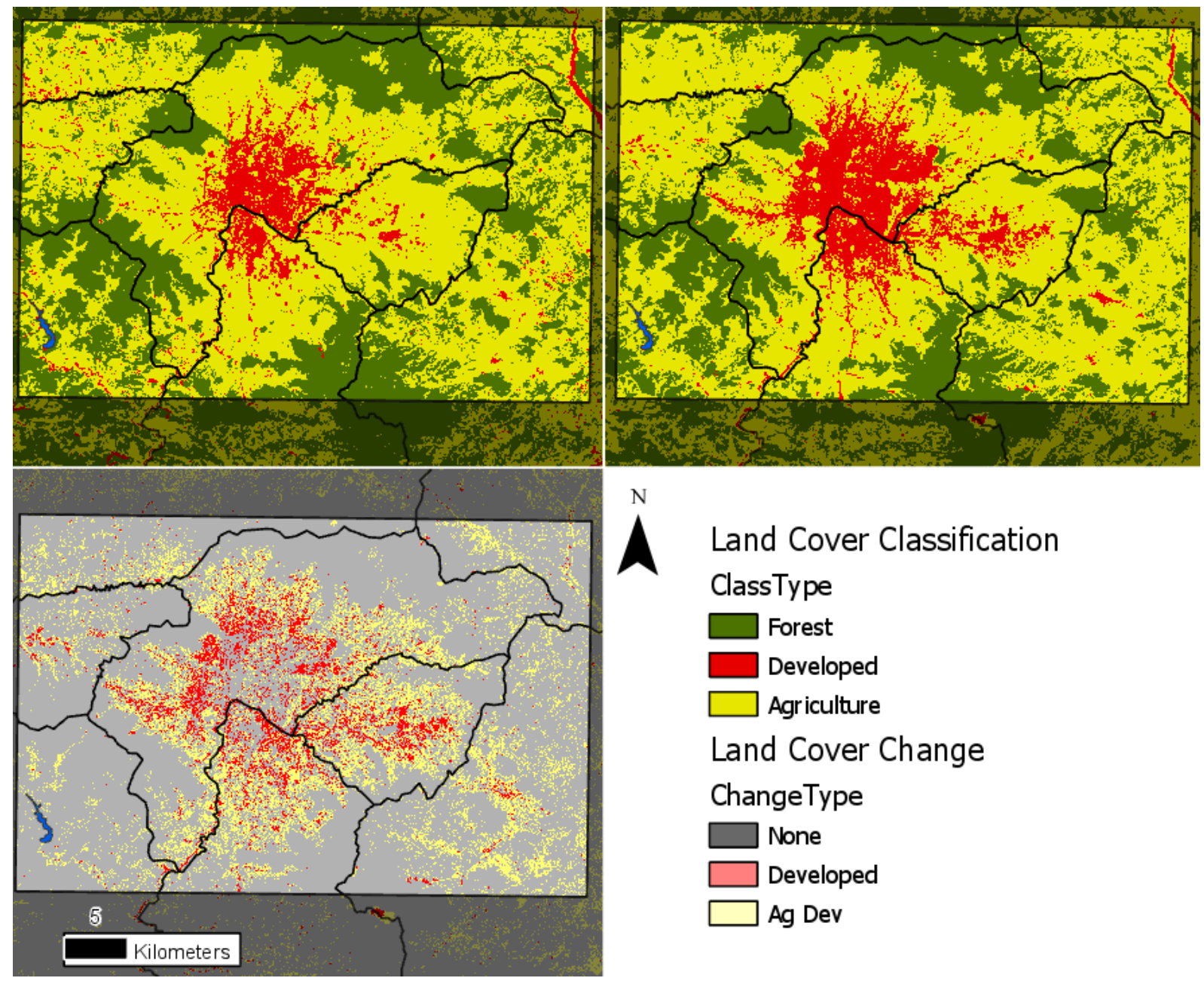

Figure 3: Land cover classifications highlighting the distribution of land cover types for the year 2000 (top left), the year 2018 (top right), and the type of change experienced during that period (bottom left). 
Table 1: Land Cover (2000 and 2018) and land Cover Change Over time by Districts.

\begin{tabular}{|c|c|c|c|c|c|c|c|c|c|c|}
\hline & \multicolumn{3}{|c|}{2000} & \multicolumn{3}{|c|}{2018} & \multicolumn{3}{|c|}{ Change \% } & \\
\hline Name & Forest & Dev & $A g$ & Forest & Dev & $A g$ & Forest & Dev & $A g$ & Name \\
\hline Kathmandu & 132.9 & 57.2 & 224.0 & 115.0 & 81.5 & 213.5 & -13.5 & 42.4 & -4.7 & Kathmandu \\
\hline Lalitpur & 44.9 & 17.1 & 86.4 & 34.4 & 26.5 & 86.2 & -23.4 & 55.5 & -0.2 & Lalitpur \\
\hline Kavrepalanchok & 97.2 & 9.1 & 147.5 & 81.4 & 3.6 & 167.1 & -16.3 & -60.6 & 13.3 & Kavrepalanchok \\
\hline Bhaktapur & 23.9 & 8.7 & 90.2 & 18.5 & 19.4 & 84.8 & -22.3 & 123.4 & -6.0 & Bhaktapur \\
\hline Makwanpur & 71.2 & 5.6 & 54.6 & 60.8 & 1.4 & 63.6 & -14.7 & -75.7 & 16.5 & Makwanpur \\
\hline Nuwakot & 40.8 & 4.9 & 57.3 & 37.5 & 0.9 & 63.2 & -8.1 & -80.8 & 10.3 & Nuwakot \\
\hline Dhading & 33.0 & 4.0 & 55.1 & 29.7 & 2.2 & 59.8 & -9.8 & -43.7 & 8.6 & Dhading \\
\hline Sindhupalchok & 24.1 & 3.0 & 39.7 & 20.4 & 1.9 & 44.3 & -15.5 & -38.9 & 11.7 & Sindhupalchok \\
\hline totals (sq. km) & 468 & 109 & 755 & 398 & 137 & 783 & -15.0 & 25.5 & 3.7 & totals (\%) \\
\hline
\end{tabular}

\subsection{Distribution of Land Surface Temperatures of Kathmandu}

One of the objectives of the research was to study the distribution of mean LSTs from 2000-2018 in the Kathmandu Valley. These results validated several important findings: A) MODIS MOD11A2 500-m pixel imagery (Figure 4) showed that the daytime mean LSTs in Kathmandu Valley was higher than the surrounding area; B) Kathmandu is the most urbanized part of the valley; therefore, it has more developed areas compared to its surroundings, which may be why the temperature is high; andC) the highest temperature in Kathmandu Valley was in the developed land among the three major types of land covers i.e. forest, agriculture, and developed land. It is clear that LST variation is largely driven by the type of and cover present.

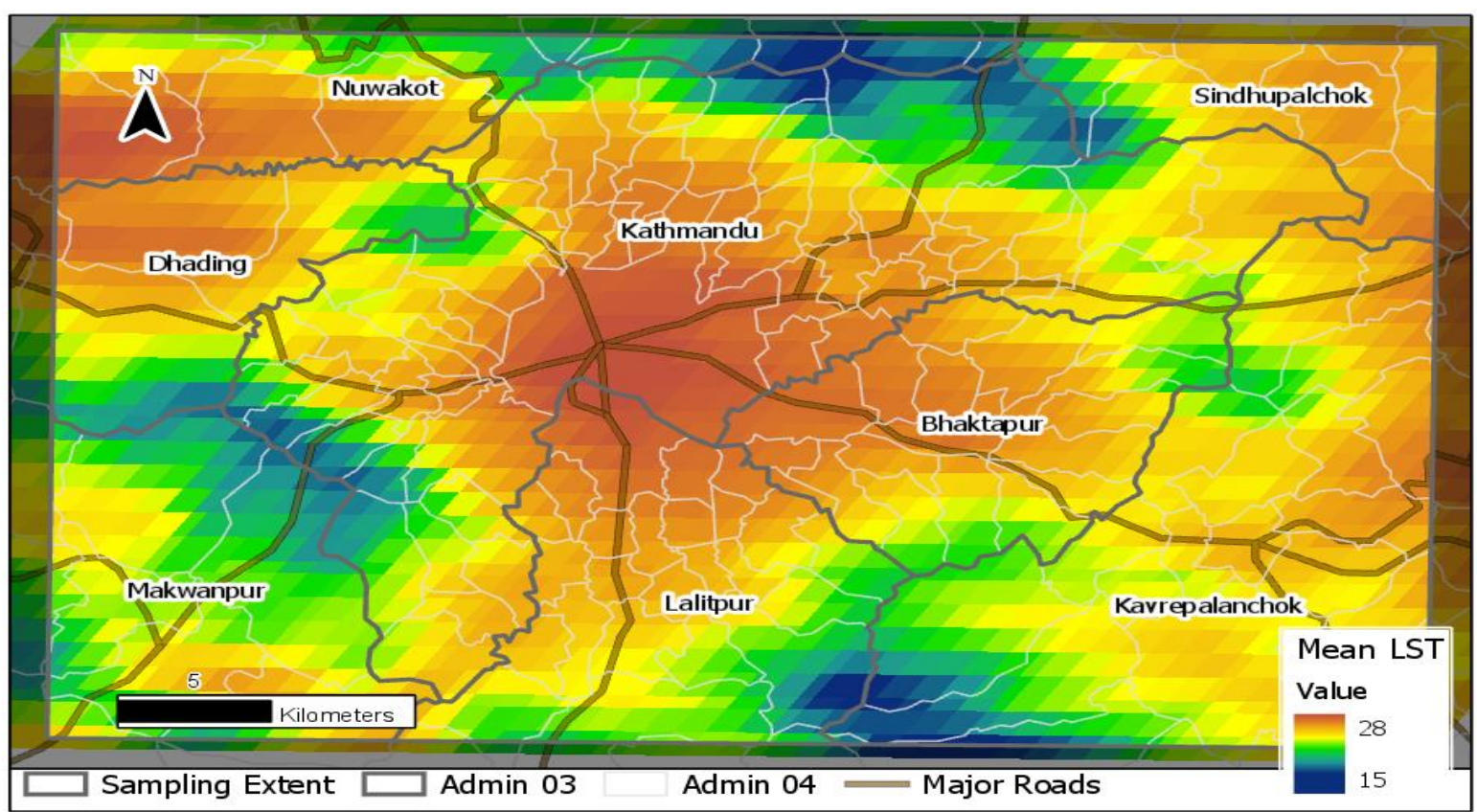

Figure 4: Mean daytime surface temperature distribution for Kathmandu during the period 2000 to 2018, driven largely by land cover such as, the heavily developed areas in central Kathmandu, and elevation. 
The variation in LSTs across the various land cover classes is evident as well. Forested land areas, as expected, are the coolest land cover, followed by agricultural lands and developed areas with mean LSTs of 20.5, 23.2, and 25.3, respectively. The difference between the forest LSTs versus those of developed and agricultural lands approximates an $\mathrm{UHI}$ potential of $5^{\circ} \mathrm{C}$. The newly developed region with the highest temperature is in the west of Kathmandu, where areas of new settlement have been expanding and large areas of forestland are being converted into agricultural land and agricultural land is being converted into urban areas (Ishtiaque et al., 2017; Thapa and Murayama, 2009; Thapa and Murayama, 2012). The center of the Kathmandu Valley is also the most populated region of the valley. However, the population growth is very high in surrounding semi-urban areas (Ishtiaque et. al., 2017). The future trend of the surface temperature is projectable based on the trends of population changes in the Kathmandu Valley. It is more likely that the current temperature of the core city is likely to be reflected in the temperature of the surrounding semi-urban areas of Kathmandu in the future if this trend continues.

\subsection{Change in LST and NDVI over time}

The LST change over time from 2000-2018 was calculated for each pixel throughout the study area using the simple linear model described in Eq. (1), where the generated $\beta$ coefficient acts as an estimate for the increase in LST values per each time step from 2000-2018 for the month and highlights each area where LSTs have significantly increased or decreased $(p<0.05)$. In Figure 5, areas colored red represent a relative annual increase of $0^{\circ} \mathrm{C}$ to $2^{\circ} \mathrm{C}$ and areas colored blue represents an annual decrease of $0.0^{\circ} \mathrm{C}$ to $2.5^{\circ} \mathrm{C}$. Pixels with statistically significant changes are denoted with black stars as these are the areas with a large magnitude change over time relative to the observed variation in values throughout the record length.

Figure 5 shows that the temperature changed significantly in areas outside the core of Kathmandu City and in those areas where new urban and semi-urban areas are expanding. For example, in the northeast portion of the image, a large clustering of pixels indicates significant changes in temperature; however, these are confined to a small location and not widespread. There are several areas within Kathmandu City that had significant increases in LSTs, although they were relatively small compared to peripheral areas. Overall, the LSTs changed significantly outside the urban Kathmandu Valley.

The NDVI change from 2000-2018 was also calculated for each pixel throughout the study area using the simple linear model described in Eq. (1), where the generated $\beta$ coefficient acts as an estimate for the increase in NDVI values per each time step. The change in NDVI from 2000-2018 displayed in Figure 6 highlights substantially more areas in which NDVI values increased or decreased significantly, compared to LSTs. Large decreases were evident, especially just north of the administrative areas of the Kathmandu and Bhaktapur districts. In contrast, many peripheral areas experienced significant increases in NDVI values, 
especially in the northwest and south central portion of the delineated study area. In each case, these findings were expected based on previous reports (Ishtiaque et al., 2017); much of it was due to increasingly intensive agriculture practices.

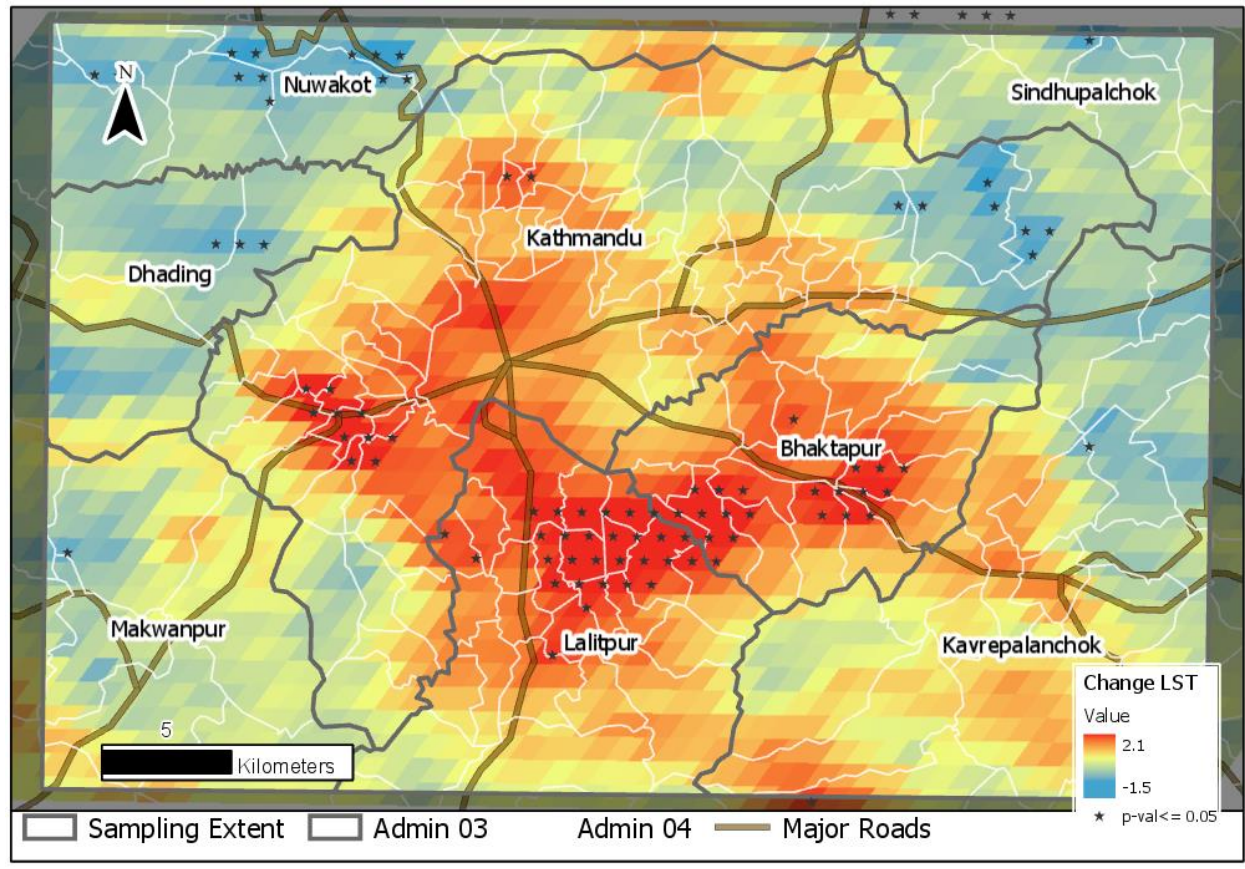

Figure 5: Distribution of estimates of the change in mean daytime land surface temperatures for Kathmandu during the period 2000 to 2018. Statistically significant changes in LST are highlighted with stars (p-value $=<0.05)$.

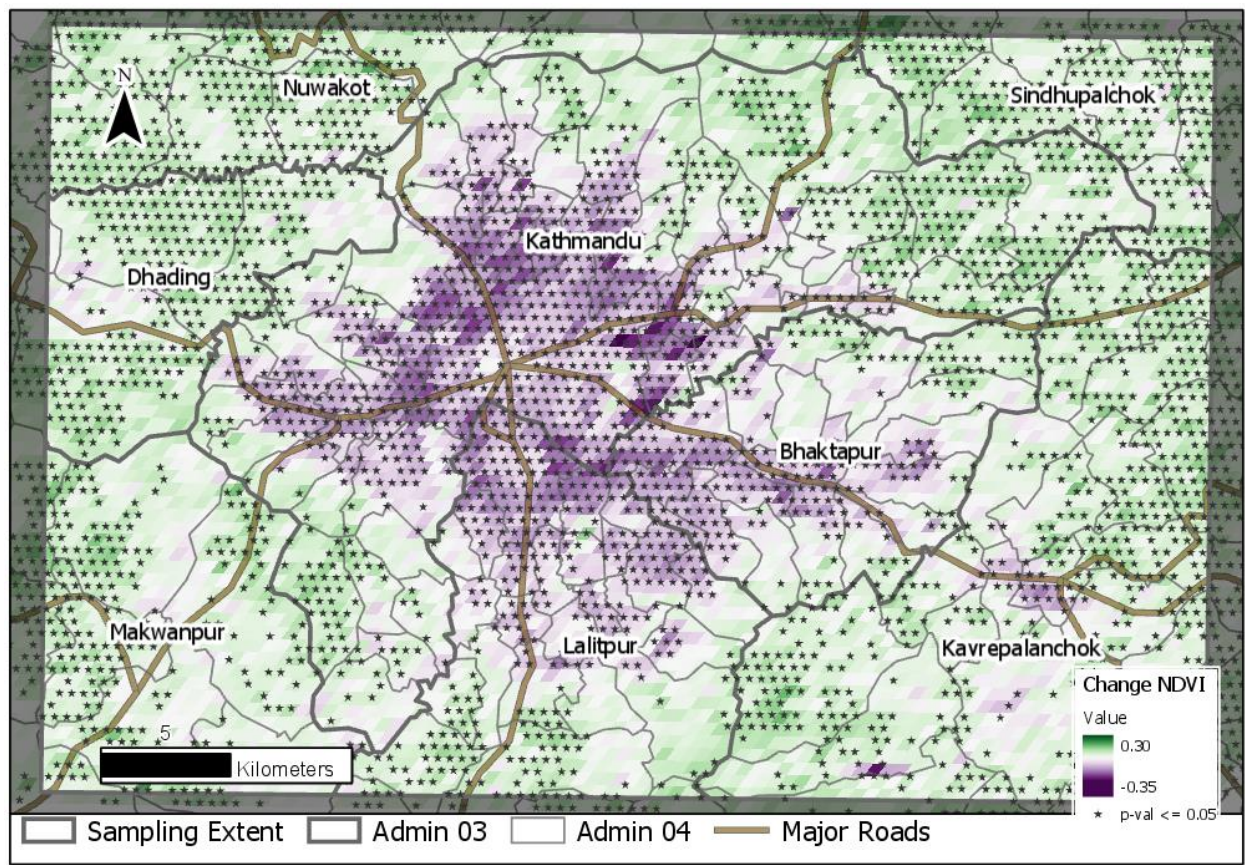

Figure 6: Distribution of estimates of the change in NDVI values for Kathmandu during the period 2000 to 2018. Statistically significant changes in NDVI are highlighted with stars (p-value $=<0.05$ ). 
PC coefficients were used to evaluate the linearity of the relationship between NDVI and LST values across all land cover types, resulting in a strong negative association of -0.65 as in Figure 7. In contrast, integration of LST and NDVI change values over time into an ordinary-least-squares (OLS) regression model indicated the predictive power of NDVI only accounted for approximately $45 \%$ of the overall variation in LSTs change over time. PC coefficients and OLS models were also applied to the NDVI and LST change values while sub-setting the global data by each land cover type (agriculture, developed, and forests). In the case of agriculture lands, the association between NDVI and LST was more linear $(\mathrm{PC}=-0.65)$ and slightly more useful for predictions ( $\sim 7 \%$ ). Forested land areas and those with high development levels had a less linear relationship between NDVI and LSTs ( -0.3 and -0.22 , respectively) and were considerably less useful for predictions ( $25 \%$, each).
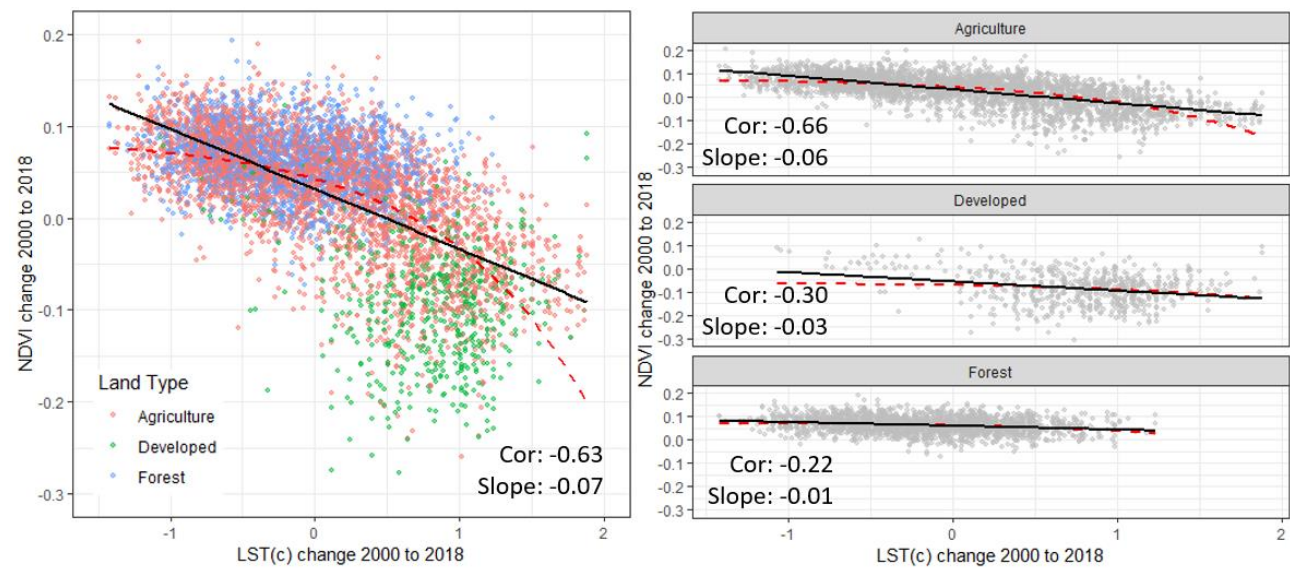

Figure 7: Least-squares-regression models to highlight the relationship between change in land surface temperature (x-axis) and temporally consistent changes in NDVI (y-axis) from 2000 to 2018 globally (left) and specifically for agriculture, developed, and forested land covers (right).

This lack of correlation and predictive power was surprising since NDVI has been highly correlated with LST (Grover and Singh, 2015; Liu et al., 2015) without reporting the decoupling of the relationship for different physical settings. This distribution pattern does not show the expected interrelationship between these parameters; thus, the findings of the current research contrast with previous findings in terms of the coupling between significant change in LSTs and NDVI and the spatial distribution of the LST and NDVI. However, the results support the results of recent research conducted in cities in similar stages of development. Cui et al. (2016) found that UHIs show global heterogeneity for several reasons, including the location's geography and socioeconomic conditions. The research also showed that socioeconomic factors and population dynamics play important roles in determining UHI in developing countries, whereas gross domestic product (GDP) plays a major role in UHI formation and its effects in developed countries. This is because the impact of socioeconomic factors such as population and GDP on the UHI are greater during early stages of the urban 
development process has not been linear and is complex to model for the type of analysis presented here. Specifically, general population characteristics are the main impact factor in land cover change and consequent development of increased surface UHI intensity in rapidly developing urban areas, such as in parts of China, whereas nationally aggregated GDP variation was the main impact factor in a developed country like the United States. This difference highlights the need for modelling efforts to incorporate additional information characterizing the spatial dynamics of the population attached to that physical area. These factors should be taken into account when studying UHI and its hazardous effects in developing city such as Kathmandu and its peripheries.

\section{Conclusions}

This study evaluated drivers of UHIs in Kathmandu using Landsat and MODIS satellite imagery and analyzed the spatial distribution of LST and NDVI in the Kathmandu Valley. The city's core had the highest temperature although the change in temperature was more significant in newly developing urban and semiurban areas. The development of new urban and semi-urban centers will increase the temperature of the region further and has potential to expand health risks among the urban population and ecosystems of the Kathmandu Valley in the future.

NDVI values also changed significantly in the Kathmandu Valley's central core and outlying areas. The magnitude of change was high in the surrounding areas compared to the valley's core. This suggests that the greenery inside the valley decreased significantly over the past two decades and the removal of vegetation is expanding towards the outer, newly developed semi-urban areas. These newly developing semi-urban areas are likely to become new urban centers that may have many of the same characteristics as the valley's core. The spatial relation of change in LST and the NDVI was not always spatially coincident, but was statistically significant. Additional research is needed to study drivers of the UHI from other perspectives in addition to land cover and vegetation changes. NDVI data has validated UHI in several big cities (Grover and Singh, 2015; Liu et al., 2015); however, this is not true in the case of Kathmandu. Cui et al. (2016) found that geography and socioeconomic variations play important roles in determining UHI. They also found that population may also have an important role in the UHI phenomenon during the early stages of urbanization. Our findings are consistent with this finding, particularly with respect to Kathmandu in the developing phase. More studies combining NDVI, population, and socioeconomic attributes are needed to understand coupled effects in UHI of Kathmandu Valley. 


\section{Acknowledgement}

This research was funded by the National Science Foundation Historically Black College and UniversitiesUndergraduate Program (NSF_HBCU_UP) Award \# HRD-1332477 and HRD-1436426.

\section{References}

Aksha S. K, Juran L., Resler L. M. 2018. Spatial and temporal analysis of natural hazard mortality in Nepal. Environmental Hazzards 17(2): 163-179.

Azevedo, J., Chapman, L., and Muller, C., 2016. Quantifying the daytime and night-time urban heat island in Birmingham, UK: A comparison of satellite derived land surface temperature and high resolution air temperature observations, Remote Sens, 8. doi:10.3390/rs8020153.

Bakrania, S., 2015. Urbanization and urban growth in Nepal, GRDC Helpdesk Research Report 1294, Birmingham, UK: GSDRC, University of Birmingham.

Chitrakar, R. M., Baker D. C., and Guaralda, M., 2016. Urban growth and development of contemporary neighborhood public space in Kathmandu Valley, Nepal. Habitat Int., 53, 30-38, doi:10.1016/j.habitatint.2015.11.006.

Cui, Y., Xu, X., Dong, J., and Qin, Y., 2016. Influence of urbanization factors on surface urban heat island intensity: A comparison of countries at different developmental phases. Sustainability, 8. doi:10.3390/su8080706.

Didan, K., 2015. MOD13Q1 MODIS/Terra Vegetation Indices 16 Day L3 Global 250 m SIN Grid V006, NASA EOSDIS Land Processes DAAC. https://doi.org/10.5067/modis/mod13Q1.006.

Grover A., and Singh, R. B., 2015. Analysis of urban heat island (UHI) in relation to normalized difference vegetation index (NDVI): A comparative study of Delhi and Mumbai, Environments, 2 (2), 125-138, doi:10.3390/environments2020125.

Haack, B. N., and Khatiwada, G., 2007. Rice and bricks: Environmental issues and mapping of the unusual crop rotation pattern in the Kathmandu Valley, Nepal, Environ. Manage. 39, 774-782, doi:10.1007/s00267-006-0167-0.

Ishtiaque A, Shrestha M., and Chhetri N., 2017. Rapid urban growth in the Kathmandu Valley Nepal: Monitoring land use land cover dynamics of a Himalayan City with Landsat Imageries, Environments, 4 (72). http://dx.doi.org/10.3390/environments4040072

Jin, M., Dickinson, R. E., and Zhang, D., 2005. The footprint of urban areas on global climate as characterized by MODIS, J Climate, 18, 1551-1565, doi:10.1175/jcli3334.1. 
Lavaysse, C., Cammalleri, C., Dosio, A., Schrier, G. V.D., Toreti, A., and Vogt, J., 2018. Towards a monitoring system of temperature extremes in Europe. Nat. Hazards Earth Syst. Sci. 18, 91-104.

Li, J.J.; Wang, X.R.; Wang, X.J.; Ma, W.C.; Zhang, H., 2009. Remote sensing evaluation of urban heat island and its spatial pattern of the Shanghai metropolitan area, China. Ecol. Complex, 6, 413-420. https://doi.org/10.1016/j.ecocom.2009.02.002.

Liu, W., Ji, C. Jiang, X., and Zhong, J., 2015. Relationship between NDVI and the urban heat island effect in Beijing area of China, SIPE Proceedings Vol 5884, Remote Sensing and Modeling of Ecosystem for Sustainability II, Editors: Gao and Shaw.

Maharjan, S., and Regmi, R.P., 2014. Grid based temperature and relative humidity distribution map of the Kathmandu Valley, J Inst Sci Technol, 19, 7-13, doi:10.3126/jist.v19i1.13819.

Ministry of Urban Development (MoUD), 2015. National Urban Development Strategy. Ministry of Urban Development, Government of Nepal, available at: http://moud.gov.np/wpcontent/uploads/2016/08/NUDS-2015-final-draft.pdf, last accessed 21 February 2017, 2015.

R Core Team. R, 2013. A language and environment for statistical computing, R Foundation for Statistical Computing, Vienna, Austria, available at: http://www.R-project.org/, last accessed 11 October 2017.

Rimal B., Zhang L., Dongjie O., Kunwar R., Zhai, Y., 2017. Monitoring urban growth and the Nepal earthquake 2015 for sustainability of Kathmandu Valley, Nepal, Land 6 (2) 42; doi:10.3390/land6020042. http://www.mdpi.com/2073-445X/6/2/42/htm.

Thapa, R. B., Murayama, Y., and Ale, S., 2008. City profile Kathmandu. Cities, 25, 45-57. doi:10.1016/j.cities.2007.10.001.

Thapa, R. B., and Murayama, Y., 2009. Examining spatiotemporal urbanization patterns in Kathmandu Valley, Nepal: Remote sensing and spatial metrics approaches, Remote Sens., 1, 534-556. doi:10.3390/rs1030534.

Thapa, R. B., and Murayama Y., 2012. Scenario based urban growth allocation in Kathmandu Valley, Nepal, Landscape Urban Plan, 105, 140-148, doi:10.1016/j.landurbplan.2011.12.007.

United Nations, Department of Economic and Social Affairs (UN DESA), 2015. World Urbanization Prospects: The 2014 Revisions, (ST/ESA/SER.A/366), available at: https://esa.un.org/Unpd/Wup/Publications/Files/WUP2014-Report.pdf, last accessed 20 February 2017.

Zakšek, K., and Oštir, K., 2012. Downscaling land surface temperature for urban heat island diurnal cycle analysis. Remote Sens. Environ, 117, 114-124, doi:10.1016/j.rse.2011.05.02. 